\title{
Regulation of gene expression by FSP27 in white and brown adipose tissue
}

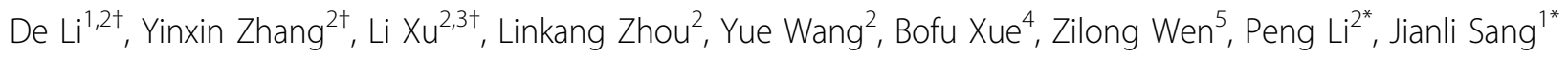

\begin{abstract}
Background: Brown and white adipose tissues (BAT and WAT) play critical roles in controlling energy homeostasis and in the development of obesity and diabetes. The mouse Fat-Specific protein 27 (FSP27), a member of the cell death-inducing DFF45-like effector (CIDE) family, is expressed in both BAT and WAT and is associated with lipid droplets. Over-expression of FSP27 promotes lipid storage, whereas FSP27 deficient mice have improved insulin sensitivity and are resistant to diet-induced obesity. In addition, FSP27-deficient white adipocytes have reduced lipid storage, smaller lipid droplets, increased mitochondrial activity and a higher expression of several BAT-selective genes. To elucidate the molecular mechanism by which FSP27 controls lipid storage and gene expression in WAT and BAT, we systematically analyzed the gene expression profile of FSP27-deficient WAT by microarray analysis and compared the expression levels of a specific set of genes in WAT and BAT by semi-quantitative real-time PCR analysis.

Results: BAT-selective genes were significantly up-regulated, whereas WAT-selective genes were down-regulated in the WAT of FSP27-deficient mice. The expression of the BAT-selective genes was also dramatically up-regulated in the WAT of leptin/FSP27 double deficient mice. In addition, the expression levels of genes involved in multiple metabolic pathways, including oxidative phosphorylation, the TCA cycle, fatty acid synthesis and fatty acid oxidation, were increased in the FSP27-deficient WAT. In contrast, the expression levels for genes involved in extracellular matrix remodeling, the classic complement pathway and TGF- $\beta$ signaling were down-regulated in the FSP27-deficient WAT. Most importantly, the expression levels of regulatory factors that determine BAT identity, such as CEBP $\alpha / \beta$, PRDM16 and major components of the CAMP pathway, were markedly up-regulated in the WAT of FSP27-deficient mice. The expression levels of these regulatory factors were also up-regulated in leptin/FSP27 double deficient mice. Interestingly, distinct gene expression profiles were observed in the BAT of FSP27-deficient mice. Taken together, these data suggest that the WAT of FSP27-deficient mice have a gene expression profile similar to that of BAT.

Conclusions: FSP27 acts as a molecular determinant that controls gene expression for a diversity of metabolic and signaling pathways and, in particular, the expression of regulatory factors, including CEBP $\alpha / \beta, P R D M 16$ and components of the CAMP signaling pathway, that control the identity of WAT and BAT.
\end{abstract}

\section{Background}

Adipose tissues play crucial roles in the development of obesity, with white adipose tissue (WAT) functioning as an energy storage organ and brown adipose tissue (BAT) functioning as an energy consumption organ [1]. BAT is especially abundant throughout the life-span of rodents and in hibernating mammals. In humans it was believed to

\footnotetext{
* Correspondence: li-peng@mail.tsinghua.edu.cn; jssang@bnu.edu.cn

+ Contributed equally

${ }^{1}$ College of Life Sciences, Beijing Normal University Xinjiekouwai Street 19, Xichen District Beijing 100875, China

${ }^{2}$ Protein Science Laboratory of the Ministry of Education, School of Life Sciences, Tsinghua University, Qinghuayuan, Haidian District, Beijing 100084, China
}

(C) $2010 \mathrm{Li}$ et al; licensee BioMed Central Ltd. This is an Open Access article distributed under the terms of the Creative Commons Attribution License (http://creativecommons.org/licenses/by/2.0), which permits unrestricted use, distribution, and reproduction in any medium, provided the original work is properly cited. present only in newborns and disappears in adults [2,3]. Interestingly, BAT and its increased activities in response to low temperature $\left(16^{\circ} \mathrm{C}\right)$ can be detected in adult humans by ${ }^{18} \mathrm{~F}$-fluorodeoxyglucose $\left({ }^{18} \mathrm{~F}\right.$-FDG) positronemission tomography-computed tomography (PET-CT), and the response negatively correlates with their increasing body mass index [4-6]. Although WAT and BAT both express a set of genes that are involved in the regulation of lipolysis, fatty acid metabolism, triacylglycerol (TAG) storage and insulin sensitivity $[7,8]$, BAT contains a large number of mitochondria and is functionally more important as a thermogenic tissue [9]. Uncoupling protein 1 (UCP1), which is uniquely expressed in BAT, plays an 
important role in the uncoupling of oxidative phosphorylation and the conversion of energy into heat to maintain normal body temperature. In addition to UCP1, type 2 iodothyronine deiondinase (DIO2) [10], elongation of very long chain fatty acid-3 (ELOVL3) [11-13], COX8b [14,15] and lipid storage droplet protein 5 (LSDP5) [16-18] are also expressed at high levels in BAT but low levels in WAT. PGC-1 $\alpha[19,20]$, a co-activator that coordinates multiple physiological cues for mitochondrial biogenesis and activity, is highly expressed in BAT but only expressed at low levels in WAT [21]. TR3, a member of the nuclear receptor super-family, is expressed in brown adipocytes upon cold exposure and inhibits adipocyte differentiation $[22,23]$. In contrast, mesoderm-specific transcript (MEST) gene expression is markedly enhanced in the WAT of mice with diet-induced and genetically caused obesity [24]. Its expression levels are positively correlated with white fat mass, which may be related to its putative lipase activity [25]. Resistin-like molecule alpha (RETNL $\alpha$ ), which shares homology with Resistin [26,27], has also been shown to be exclusively expressed in the stromal vascular fraction of WAT [28].

The exact origin of brown and white adipocytes and their developmental relationship is not clear. Brown and white adipocytes were previously considered to be derived from a common preadipocyte pool [29]. However, recent studies have suggested instead that brown adipocytes and muscle cells share a similar precursor, based on the observation that knock-down of PRDM16, a BAT-specific gene $[15,30]$, switched the fate of brown adipocytes to that of muscle cells [31]. PRDM16 appears to be a co-factor for CEBP $\beta$ and PGC1 $\alpha / \beta$, which up-regulates the expression of many BAT-selective genes while down-regulating the expression of WAT-selective genes $[15,32]$. Differentiated WAT is able to develop a BATlike phenotype under special conditions including cold exposure or after the administration of a $\beta 3$-agonist to WAT depots [33-35]. PPAR $\gamma$ has been shown to be required for the conversion of WAT to a BAT-like tissue based on the observation that this conversion is blocked in cold-acclimatized PPAR $\gamma$-mutant (P465L) mice [36]. Over-expression of the $C E B P \beta$ gene in $C E B P \alpha$-deficient mice results in increased expression of the Gs $\alpha$ subunit, enhanced mitochondrial biogenesis and increased UCP1 expression in WAT [37]. The WAT in mice over-expressing FOXC2 is converted into a BAT-like tissue with a corresponding increase in the expression levels of PGC1, UCP1 and cAMP pathway proteins [38]. Although many factors and regulatory pathways have been shown to play important roles in regulating the conversion of WAT to a tissue with a BAT-like phenotype and function, the upstream signals or factors that determine the fate of BAT vs. WAT and initiate the conversion of WAT to a BAT-like tissue remain unclear.
CIDE proteins, including CIDEA, CIDEB and Fat specific protein 27 (FSP27, also known as CIDEC in humans), have been identified as important regulators of various metabolic pathways [39]. Our previous work demonstrated that CIDEA is expressed at high levels in BAT, whereas CIDEB is expressed at high levels in liver. Mice with a deficiency in both CIDEA and CIDEB have a higher energy expenditure, enhanced insulin sensitivity and a resistance against high-fat-diet-induced obesity and diabetes $[40,41]$. The FSP27 protein was detected at high levels in WAT and at moderate levels in BAT [42]. Furthermore, CIDE family proteins have been shown to be associated with the lipid droplet enriched fraction [42-45] and over-expression of FSP27 promotes TAG storage [44]. FSP27-null mice have a lean phenotype and are resistant to diet-induced obesity $[42,46]$. In addition, the WAT of FSP27-deficient mice has smaller lipid droplets as well as an increased mitochondrial size and activity $[42,46]$. In particular, several genes that are preferentially expressed in the BAT (UCP1, DIO2 and CIDEA) and several regulatory factors (PPAR $\alpha / \gamma$, PGC1) are up-regulated in the WAT of FSP27-deficient mice [42]. Therefore, the WAT of FSP27 deficient mice appear to adapt certain features similar to those found in BAT. The regulatory pathways and the underlying mechanism of FSP27-mediated transcriptional regulation in WAT and $\mathrm{BAT}$, however, remain unclear. Using microarray and semi-quantitative real-time PCR (qPCR) analyses, we demonstrated that the WAT of FSP27 or FSP27/leptin deficient mice have markedly increased expression of many BAT-selective genes and decreased expression of WAT-selective genes. In addition, the expression levels of many genes involved in mitochondrial oxidative phosphorylation, lipolysis, fatty acid oxidation and the TCA cycle were up-regulated in the WAT of FSP27-deficient mice, which is consistent with their increased mitochondrial activity and whole-body metabolism. In contrast, genes involved in the classic complement pathway, extracellular matrix remodeling and the TGF- $\beta$ signaling pathway were down-regulated in the WAT of FSP27-deficient mice. Most importantly, the expression of regulatory factors that activate the expression of BAT-selective genes was upregulated in the WAT of FSP27 deficient mice, providing a molecular explanation for the increased expression of BAT-selective genes and the acquisition of BAT-like properties in the WAT of FSP27-deficient mice.

\section{Results}

\section{Alteration of the gene expression program in FSP27-} deficient mice as determined by microarray analysis

To determine the extent of the physiological changes required to convert WAT into a BAT-like tissue and to systematically analyze the transcriptional program of WAT in FSP27-deficient mice, whole gene microarray analysis was performed using Affymetrix oligonucleotide 
arrays separately hybridized with RNA from the WAT of wild-type and FSP27-deficient null mice. The expression of approximately 22,700 transcripts represented on the Affymetrix mouse genome 430 2.0A microarray chips was quantified in pooled WAT samples from five each of the wild-type and FSP27-deficient mice. Duplicate hybridizations were performed for each sample. The genes were filtered according to the criteria of a decrease $\geq 30 \%\left(2^{-0.5}\right)$ or increase $\geq 1.41$-fold $\left(2^{0.5}\right)$ in FSP27-deficient mice and consistency between the duplicate experiments. After collapsing the dataset from adjusted probes to symbols by GSEA, the expression levels of 2,870 of 5,923 genes were changed in the WAT of $F S P 27^{-1-}$ mice (48.5\%). Among them, 1,037 genes (36.1\%) were increased, whereas 1,833 genes $(63.9 \%)$ were decreased. Notably, the 10 most highly elevated genes (Table 1) include COX8b (40-fold increase), ELOVL3 (12-fold increase), TR3 downstream gene 2 (NDG2, 8-fold increase), CIDEA (8-fold increase) and cytochrome c oxidase subunit VIIa polypeptide (COX7A1, 6-fold increase). Interestingly, COX8b (a pseudogene), ELOVL3, CIDEA and COX7A1 have been reported to be highly expressed in BAT but not WAT $[14,15]$. Pyruvate dehydrogenase kinase isozyme 4 (PDK4), an enzyme involved in pyruvate metabolism [47], and the lipid droplet binding protein LSDP5 were also significantly increased. Overall, the 10 most upregulated genes in the WAT of FSP27-deficient mice comprised mostly genes selectively expressed in BAT. In contrast, the 10 most down-regulated genes involved in diverse pathways, such as proteinase 3 (PRTN3) [48] and retinitis pigmentosa GTPase regulator (RPGR) [49]. Another of the 10 most down-regulated proteins is MEST, a protein expressed at high levels in WAT but not in BAT [24].

The pathways that are altered in the WAT of FSP27deficient mice were determined by GSEA analysis. There were extensive changes in the expression of genes involved in many different metabolic pathways in the WAT of FSP27-deficient mice. Most strikingly, the expression of many proteins that localize to mitochondria were significantly up-regulated (Figures $1 \mathrm{~A} \& 1 \mathrm{~B}$ and Additional file 1). These genes are involved in the Krebs/TCA cycle (20 of 36 genes were up-regulated), the electron transport chain (ETC, 68 of 110 genes were up-regulated), mitochondrial fatty acid $\beta$-oxidation (12 of 17 genes were up-regulated) and fatty acid degradation (13 of 33 genes were up-regulated). These data are consistent with our previous observation that mitochondrial biogenesis and activity is increased in the WAT of FSP27-deficient mice [42]. In addition, the mRNA levels of many genes involved in glycolysis, gluconeogenesis, cholesterol biosynthesis, pantothenate and CoA biosynthesis, heme biosynthesis, nitrogen metabolism, ROS generation and the proteasome pathway were significantly up-regulated (Figure 1A, and Additional file 1). Microarray analysis also demonstrated

Table 1 The ten most up-regulated and ten most down-regulated genes in the WAT of FSP27-null mice

\begin{tabular}{|c|c|c|}
\hline Name & Gene Title & Fold \\
\hline \multicolumn{3}{|c|}{ Ten most upregulated genes } \\
\hline COX8B & cytochrome c oxidase, subunit 8B pseudogene & 40.06 \\
\hline ELOVL3 & elongation of very long chain fatty acids (FEN1/Elo2, SUR4/Elo3, yeast)-like 3 & 11.9 \\
\hline NDG2 & Nur77 downstream gene 2 & 8.35 \\
\hline CIDEA & cell death-inducing DFFA-like effector a & 8.22 \\
\hline COX7A1 & cytochrome c oxidase subunit VIla polypeptide 1 (muscle) & 6.74 \\
\hline CA1 & carbonic anhydrase I & 6.72 \\
\hline PDK4 & pyruvate dehydrogenase kinase, isozyme 4 & 5.83 \\
\hline CCRN4L & CCR4 carbon catabolite repression 4-like (S. cerevisiae) & 5.69 \\
\hline NAP1L5 & nucleosome assembly protein 1-like 5 & 5.63 \\
\hline 9530008L14RIK & RIKEN cDNA 9530008L14 gene & 5.59 \\
\hline \multicolumn{3}{|c|}{ Ten most downregulated genes } \\
\hline PRTN3 & proteinase 3 (serine proteinase, neutrophil, Wegener granulomatosis autoantigen) & -26.45 \\
\hline RPGR & retinitis pigmentosa GTPase regulator & -23.68 \\
\hline IGL-V1 & immunoglobulin lambda chain, variable 1 & -18.31 \\
\hline MEST & mesoderm specific transcript homolog (mouse) & -14.68 \\
\hline EAR11 & eosinophil-associated, ribonuclease A family, member 11 & -13.50 \\
\hline Tsr2 & TSR2, 20 S rRNA accumulation, homolog (S. cerevisiae) & -13.15 \\
\hline NAP1L3 & nucleosome assembly protein 1-like 3 & -12.85 \\
\hline MS4A6D & membrane-spanning 4-domains, subfamily A, member 6D & -11.98 \\
\hline SFRP5 & secreted frizzled-related protein 5 & -11.88 \\
\hline TOP2A & topoisomerase (DNA) ॥ alpha $170 \mathrm{kDa}$ & -10.89 \\
\hline
\end{tabular}


A
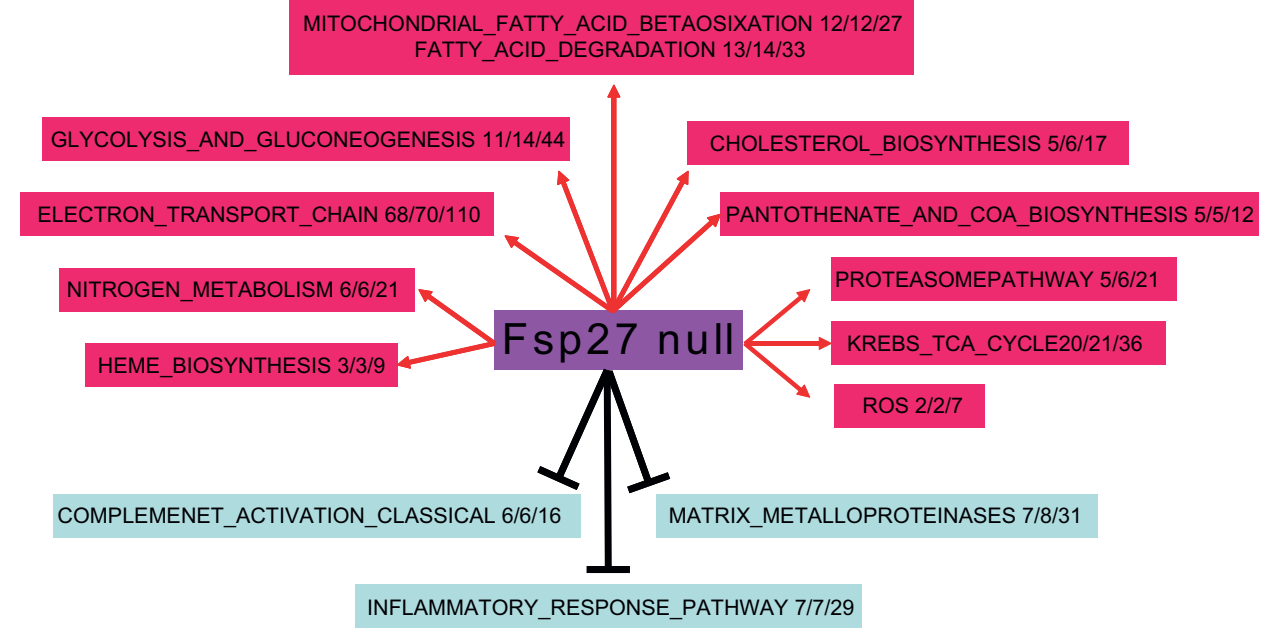

B

KREBS_TCA_CYCLE 20(21)/21(23)/36

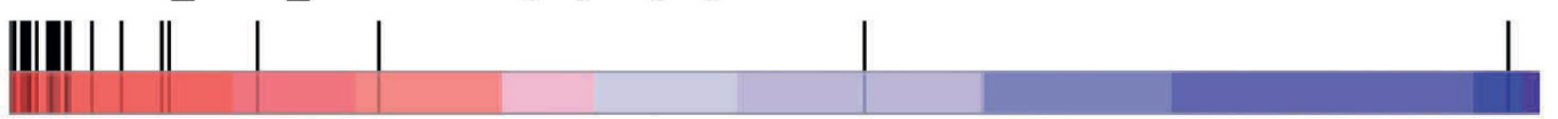

ELECTRON_TRANSPORT_CHAIN 68(74)/70(78)/110
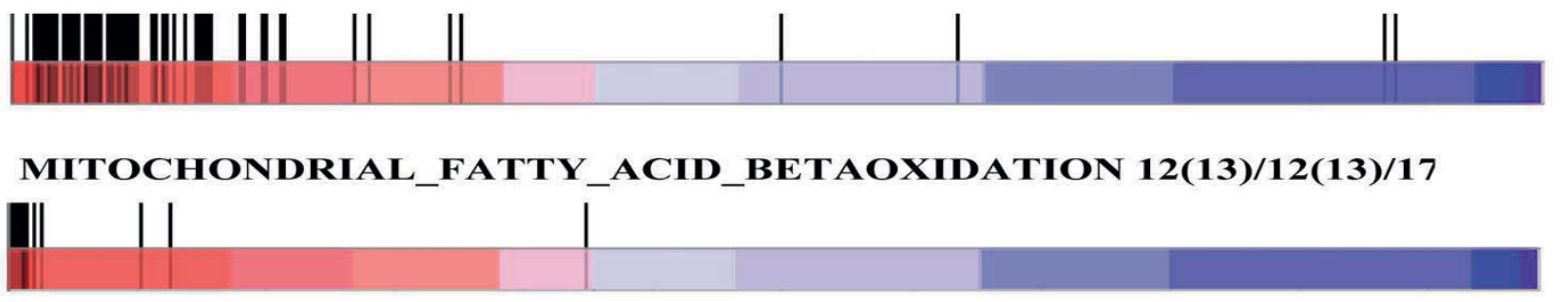

Figure 1 Dramatically altered transcriptional network in the WAT from FSP27-deficient mice by microarray analysis. A) The most significant up-regulated and down-regulated pathways in the WAT of FSP27-null mice were identified using Gene Set Enrichment Analysis (GSEA). The last number of each pathway represents the total number of genes in one gene set. The middle number represents the number of genes with an altered expression pattern (using the criteria described above), and the first number represents the number of up-regulated or down-regulated genes in the gene set. B) The pathways that were significantly up-regulated, as revealed by enrichment plot analysis, were the Krebs-TCA cycle, the electron transport chain and the mitochondrial fatty acid $\beta$ oxidation pathway. The denotation of the numbers in this figure is as follows: The number of genes having a higher than $2^{0.5}$-fold increase (the number of genes having a higher than 1 -fold increase in expression)/the number of genes with an altered expression pattern as determined by microarray in the WAT of Fsp27-/- mice (total number of genes detected by the microarray)/total number of genes in a specific pathway.

that some of the proteins normally expressed in BAT, such as PGC1 $\alpha$, UCP1 and DIO2, were expressed at high levels in the WAT of FSP27-deficient mice. Furthermore, factors that inhibit BAT differentiation, such as RB/p107, were down-regulated in the WAT of $F S P 27^{1-}$ mice (Additional file 2). These data are consistent with our previous observations [42].

The classic complement pathway, which plays an important role in the initiation of the inflammatory response, was significantly down-regulated in the WAT of FSP27-deficient mice (6 of 16 genes were downregulated, including complement component genes C1QA, C1QB, C1R, C1S, C2 and C6 (Additional file
2). Extracellular matrix proteins, including 15 members of the collagen family in particular, were significantly down-regulated (Additional file 3). Matrix metalloproteinase pathway (MMP) genes, including matrix metallopeptidases 7, 14 and 16 and the tissue inhibitor of metallopeptidase (TIMP) 1-4 (Additional file 3), were also significantly down-regulated. Some genes involved in the TGF- $\beta$ pathway were also down-regulated (Additional file 3). Furthermore, microarray analysis also showed that IRS3, AKT2 and GLUT4, three genes that are crucial for the regulation of insulin sensitivity, were significantly up-regulated (Additional file 2). These data are in accordance with our previous 
observation that FSP27-deficient mice had increased insulin sensitivity [42].

The profound increase in mitochondrial activity and the up-regulation of mitochondrial proteins can likely be attributed to the increased expression of PGC1, PPAR $\alpha$ and PPAR $\gamma$, as had been previously seen in the WAT of FSP27-deficient mice. The gene expression profile in the WAT of FSP27-deficient mice was compared with that of differentiated brown fat cells that were PGC1 $\alpha$ - and PGC1 $\beta$-deficient using Gene Set Enrichment Analysis (GSEA) [50]. Among the 1,037 transcripts that were significantly up-regulated in the WAT of FSP27-deficient mice, a significant percentage of them $(303,29.2 \%)$ were down-regulated in the $\mathrm{PGC} 1 \alpha^{-/}$- differentiated brown fat cells expressing an siRNA specific for PGC1 $\beta$ knockdown, suggesting that those 303 genes are downstream targets of PGC1 $\alpha$ and PGC1 $\beta$ (Figure 2). Comparison of the gene expression profile in the WAT of FSP27-deficient mice with that in PPAR $\gamma 2$ over-expressing NIH3T3 cells and the WAT of PPAR $\alpha$-deficient mice, 265 of the $1,037(25.6 \%)$ genes were significantly up-regulated in the PPAR $\gamma 2$ over-expressing NIH3T3 L1 cells, whereas 122 of the $1,037(11.8 \%)$ genes were down-regulated in the WAT of PPAR $\alpha$ null mice (Figure 2). These data suggest that FSP27 acts upstream to control the expression

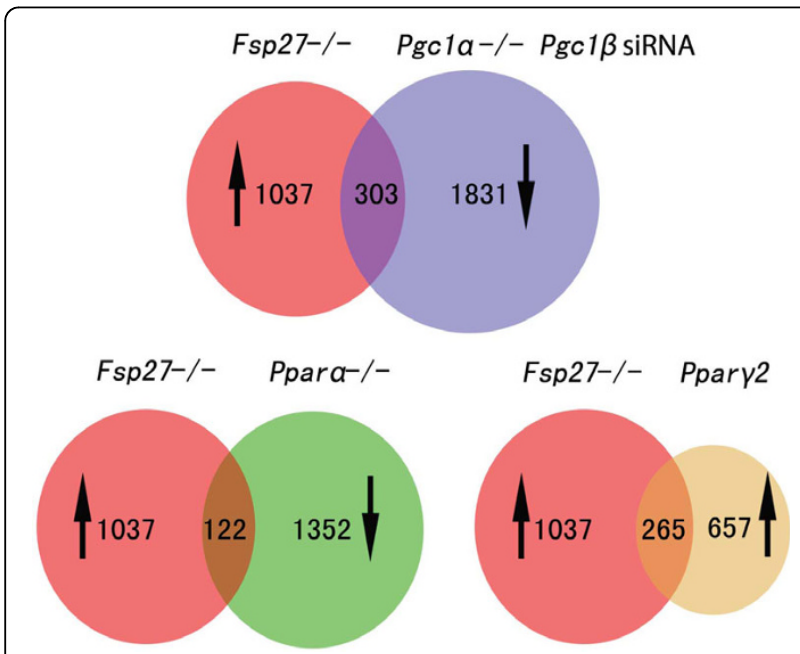

Figure 2 Comparison of the gene expression profile of FSP27deficient mouse white adipocytes with that of Pgc1 $\alpha / \mathrm{Pgc} \beta$ double deficient mouse brown adipocytes, the Ppar $\alpha$-deficient mouse WAT or the cells over-expressing PPAR $\gamma 2$. The upregulated genes $(\uparrow)$ in the white adipocytes of FSP27-null mice were compared with the following: 1) the down-regulated genes $(\downarrow)$ in Pgcl $\alpha^{-/-}$differentiated brown adipocytes expressing a siRNA specific for Pgc1 $\beta$ (Pgc1 $\alpha^{-/-}$PGC1 $\beta$ siRNA), 2) the down-regulated genes $(\downarrow)$ in the WAT of Ppar $\alpha^{-/-}$mice $\left(\right.$Ppar $\left.^{-/-}\right)$or 3 ) the up-regulated genes $(\uparrow)$ in the PPAR $\gamma 2$ over-expressing $\mathrm{NIH}-3 \mathrm{~T} 3$ cells (PPAR $\gamma 2)$. The number in the over-lapping area represents the number of genes that have conserved changes between the two cell types in the comparison. of regulatory factors such as PGC $1 \alpha$ and PPAR $\alpha / \gamma$ and thus affect the expression of the downstream targets of these regulatory factors, such as UCP1, DIO2 and CIDEA.

\section{Validation of the gene expression program in the WAT and BAT of FSP27-deficient mice by quantitative real-time PCR analysis}

To validate our microarray data, qPCR analysis was used to analyze the expression levels of representative genes taken from a variety of pathways in the WAT and BAT of FSP27- deficient mice. In a consistent manner, the expression levels of genes selectively expressed in BAT, including COX8b, ELOVL3 and UCP1, were dramatically up-regulated in the WAT of FSP27-deficient mice (85-, 140- and 35 -fold increases, respectively; Figure $3 \mathrm{~A})$. The expression levels of LSDP5 were also up-regulated (12-fold increase) in FSP27-deficient WAT. Given that FSP27 is also expressed in BAT, the expression levels of these genes were then examined in the BAT of FSP27-deficient mice. Surprisingly, there were similar levels of COX8b, LSDP5 and UCP1, but reduced expression of ELOVL3 in the BAT of FSP27 $7^{1-}$ mice (Figure 3B). Because the expression levels of many genes in various metabolic pathways are affected by obesity, we generated leptin and FSP27 double deficient mice $\left(o b / o b / F S P 27^{1-}\right)$ and examined the expression levels of BAT-selective genes in the WAT of these animals. Consistent with the previous observations, the levels of COX8b, LSDP5 and ELOVL3 were significantly elevated (125-, 30- and 230-fold increases) in the WAT of $o b / o b / F S P 27$ deficient mice compared with that of $o b / o b$ mice (Figure 3C), suggesting that the WAT of $o b / o b /$ FSP27 $7^{-1}$ mice also acquired certain BAT-like properties despite the significantly higher lipid accumulation in these obese mice.

The expression levels of genes selectively expressed in the WAT were also examined by qPCR, which revealed that the mRNA levels of MEST were significantly reduced (approximately 10-fold lower compared with that of wild-type mice, Figure 3D) in the WAT of FSP27-deficient mice. qPCR on another WAT-selective gene, resistin-related protein alpha (RETNL $\alpha$ ), revealed significantly lower mRNA levels for RETNL $\alpha$ (5-fold decrease) in the WAT of FSP27-deficient mice, suggesting that the expression of WAT-selective genes was suppressed in FSP27-deficient WAT. As an endocrine organ, WAT can secrete various adipocytokines and inflammatory cytokines, such as adiponectin, leptin and TNF $\alpha$. There was an increase in adiponectin levels and a reduction in leptin expression in the WAT of FSP27deficient mice, which is consistent with their lean and insulin sensitive phenotypes (Figure 3D). No difference in the expression of TNF $\alpha$ was observed between wild-type and FSP27-deficient WAT (Figure 3D). 
A

WAT
B

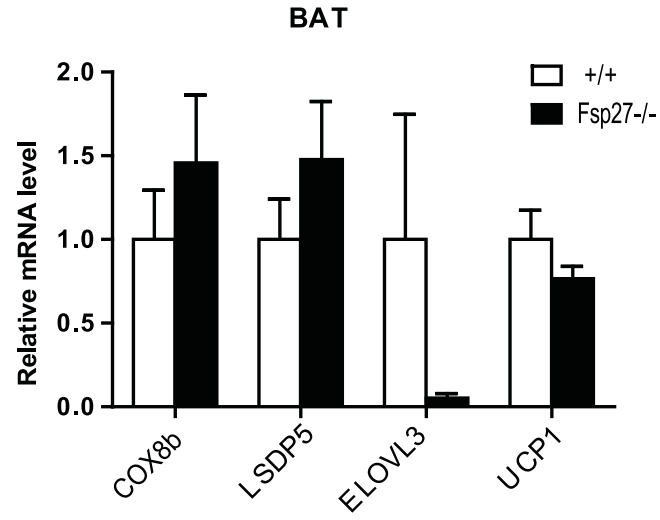

E
C

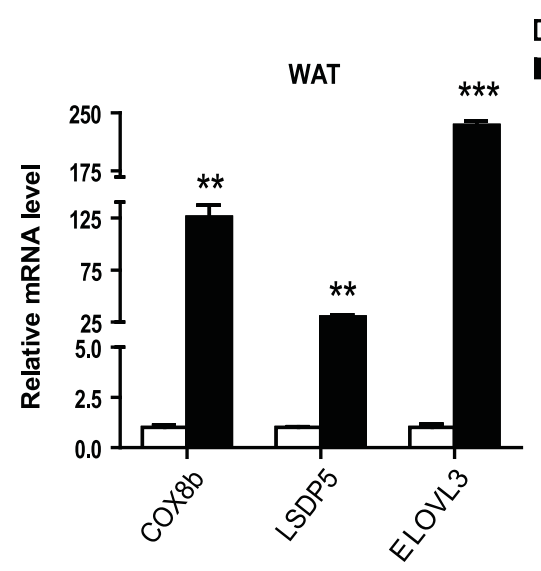

D

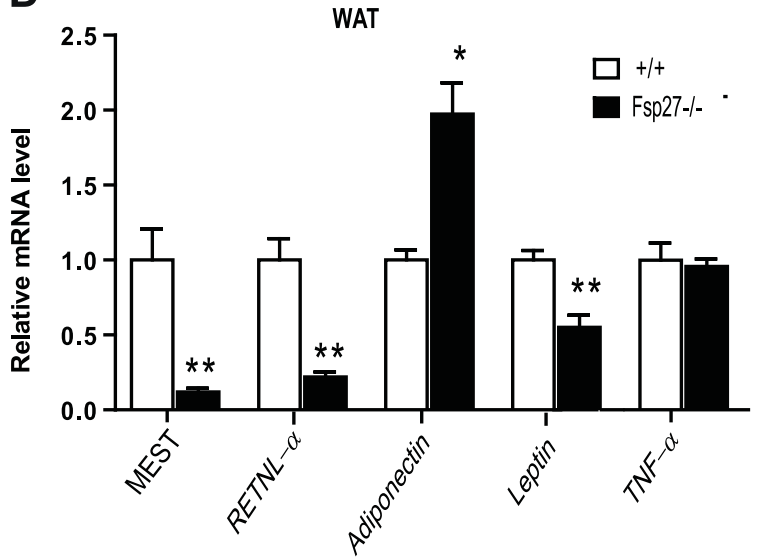

$\mathbf{F}$

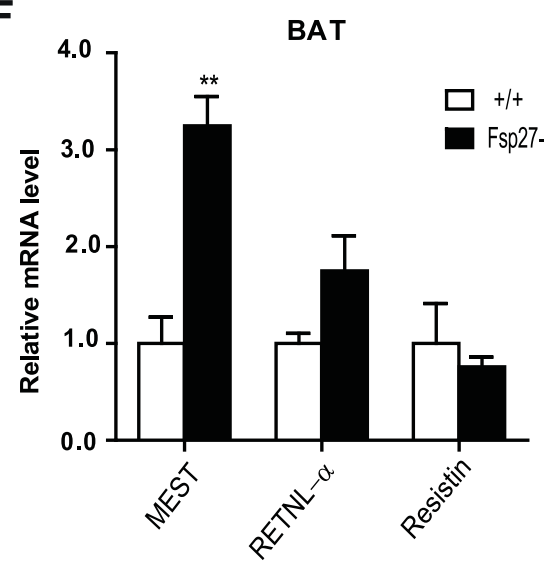

Figure 3 Up-regulation of BAT-selective genes and down-regulation of WAT-selective genes in the WAT of FSP27-deficient mice. (A \& B) Relative expression levels of BAT-specific genes (COX8b, LSDP5, ELOVL3 and UCP1) in the WAT (A) and BAT (B) of wild-type (+/+) and FSP27-deficient $\left(\right.$ FSP2 $\left.27^{\prime}\right)$ mice. (C) Expression levels of BAT-specific genes in the WAT of leptin-deficient (ob/ob) and leptin/FSP27 double-deficient (ob/ob/FSP27') mice. (D \& E) Relative mRNA levels of WAT-selective genes (MEST, RETNL $\alpha$, leptin, adiponectin and TNF $\alpha$ ) in the WAT of wild-type (+/+) and FSP27-null $\left(\right.$ FSP2 $7^{\prime-}$ ) mice, leptin-deficient (ob/ob) and leptin/FSP27 double-deficient (ob/ob/FSP27 $\left.{ }^{\prime}\right)$ mice (D) and in the BAT of wild-type $(+/+)$ and FSP27-null $\left(\right.$ FSP27 $\left.{ }^{\prime}\right)$ mice. (E). The bars represent the mean \pm S.E.M. ${ }^{* *} P<0.001$, ${ }^{* * P}<0.01$ and ${ }^{*} P<0.05$. The expression levels of each gene were assessed by semi-quantitative real-time PCR analysis. Three-month-old male mice were used in the analyses depicted in this and following figures unless otherwise noted. 
Down-regulation of MEST (4-fold decrease) and up-regulation of adiponectin (10-fold decrease) were also observed in the WAT of $o b / o b / F S P 27^{1-}$ mice compared with $o b / o b$ mice. Surprisingly, the mRNA levels of RETNL $\alpha$ were up-regulated in the WAT of $o b / o b /$ FSP27 ${ }^{1-}$ mice (2.5-fold increase, Figure 3E). The expression levels of MEST and RETNL $\alpha$ in the BAT of FSP27deficient mice were higher than those of wild-type mice (3.2- and 1.75-fold increases for MEST and RETNL $\alpha$, respectively; Figure 3F). Previous reports showed that ectopic expression of MEST markedly enlarged the size of adipocytes and that its expression levels were positively correlated with larger adipocytes [24]. Increased MEST expression is consistent with our previous observation that the BAT of FSP27-deficient mice had larger lipid droplets and increased TAG accumulation [42]. The expression levels of resistin, another WAT-selective gene, were similar in the BAT of both wild-type and FSP27-deficient mice (Figure 3F).

The expression levels of genes involved in various metabolic pathways, including lipid metabolism, uncoupling activity and mitochondrial electron transport chain activity, were then examined. The expression levels of genes involved in the fatty acid synthesis pathway, including ACC1 (2.5-fold increase), ACC2 (10-fold increase), and fatty acid synthase (FAS, 5-fold increase), were upregulated in the WAT of $F S P 27^{1-}$ mice (Figure 4A). The expression levels of genes involved in the mitochondrial oxidative pathway (Cyto-C, COX4 and CPT1) and the lipoprotein pathway, including the LDL receptor (LDLR, 4-fold increase) and Lipoprotein lipase (LPL, 2.6-fold increase), were significantly up-regulated in the WAT of FSP27-deficient mice (Figure 4A). Interestingly, UCP3, a mitochondrial uncoupling protein that is homologous to UCP1, is also significantly increased, suggesting an increase in the uncoupling activity of the WAT of FSP27deficient mice. The expression levels of ACC1, FAS, HSL, LDLR and COX 4 were also up-regulated in the BAT of $F S P 27^{-1-}$ mice, whereas the mRNA levels for UCP3, CPT1, LPL and adipsin were down-regulated in the BAT of FSP27-deficient mice (Figure 4B).

To determine whether the expression levels of genes in the classic complement and extracellular matrix remodeling pathways were indeed reduced in the WAT of FSP27 ${ }^{1-}$ mice, as indicated by the microarray analysis, the expression levels of complement factor 2 (C2), TIMP2/4, Fibronectin1 (FN1), Collagen 3 alpha (COL3- $\alpha$ ) and 6 alpha1 (COL6- $\alpha 1$ ) were measured by qPCR. The levels of TIMP2 and TIMP4 were significantly reduced in the WAT of FSP27-deficient mice (90\% and 70\% reduction for TIMP2 and TIMP4, respectively; Figure $4 \mathrm{C}$ ). The levels of $\mathrm{C} 2$, COL3- $\alpha$ and COL6- $\alpha 1$ were also reduced in the FSP27deficient WAT $(70 \%, 90 \%$ and 50\% reductions, respectively; Figure 4C). Interestingly, lower levels of TIMP2
(70\% lower) but higher levels of TIMP4 (7.8-fold higher) and COL6- $\alpha 1$ (6 fold higher) were observed in the WAT of $o b / o b / F S P 27-$ deficient mice (Figure 4D). No differences in the levels of COL $3 \alpha 1, \mathrm{C} 2$ or Fibronectin1 were observed between $o b / o b$ and $o b / o b / F S P 27^{/-}$mice (Figure 4D).

Given that lipid metabolism and mitochondrial activity are controlled by many regulatory factors in WAT and $B A T$, the expression levels of genes involved in the TGF- $\beta$ and cAMP pathways and of genes involved in the regulation of adipogenesis were analyzed. While the mRNA level of TGF- $\beta 1$ was similar in the WAT of both wild-type and FSP27-deficient mice, the mRNA levels for TGF- $\beta$-receptor 2 (TGF $\beta$-R2) and TGF $\beta$-induced protein (TGF- $\beta \mathrm{i})$, an extracellular matrix molecule induced by TGF- $\beta$ that mediates the adhesion and spreading of different cell types [51], were significantly down-regulated in the WAT of FSP27-deficient mice ( $40 \%$ and $50 \%$ reduction, respectively; Figure $5 \mathrm{~A}$ ). Interestingly, SMAD4, a downstream mediator of the TGF- $\beta$ pathway, was significantly up-regulated (Figure 5A) in the WAT of FSP27-deficient mice. The expression levels of SMAD4 were also increased in the WAT of $o b / o b /$ $F S P 27^{1-}$ mice compared with that of $o b / o b$ mice (Figure $5 \mathrm{~B})$, whereas no difference in the expression levels of TGF $\beta-R 2$ and TGF- $\beta$ i was observed in the WAT of $o b /$ $o b$ and $o b / o b / F S P 27^{/-}$mice (Figure 5B).

The expression levels of several regulatory factors, including CEBP $\alpha$ and CEBP $\beta$, PREF-1, PRDM16, TR3 and components of the CAMP pathway, were further analyzed. The expression levels of CEBP $\alpha$ and CEBP $\beta$, which are transcriptional factors controlling adipocyte differentiation and PPAR $\gamma$ expression, were significantly increased in the WAT of FSP27-deficient mice (Figure $5 C)$, which is consistent with the increased PPAR $\gamma$ expression [42]. In contrast, the expression levels of CEBP $\beta$ were significantly reduced in the BAT of FSP27deficient mice (Figure 5D). Interestingly, the expression of PREF-1, a unique preadipocyte marker, was reduced in the WAT of FSP27-deficient mice, whereas its expression level in the BAT was similar between wildtype and $F S P 27^{-1-}$ mutant mice (Figure 5C \&5D). The expression levels of PRDM16 in the WAT of FSP27/mice were also significantly up-regulated compared with that of wild-type mice. The expression of TR3 was decreased in the BAT of FSP $27^{-1-}$ mice (Figure 5D). Importantly, there was a significantly increased expression of the $\beta 3$-adrenergic receptor ( $\beta 3$-AR, 3.5-fold increase, Figure $5 \mathrm{C}$ ), the protein kinase A catalytic subunit- $\alpha$ (PKAC- $\alpha, 1.8$-fold increase) and the Gs alpha subunit (Gs- $\alpha)$. The increased expression of genes involved in the cAMP pathway could contribute to the activated metabolism and increased UCP1 expression [42] found in the WAT of FSP27-deficient mice. The expression levels of CEBP $\alpha / \beta$, PRDM16, $\beta 3-\mathrm{AR}$, PKAC- $\alpha$ and Gs- $\alpha$ 


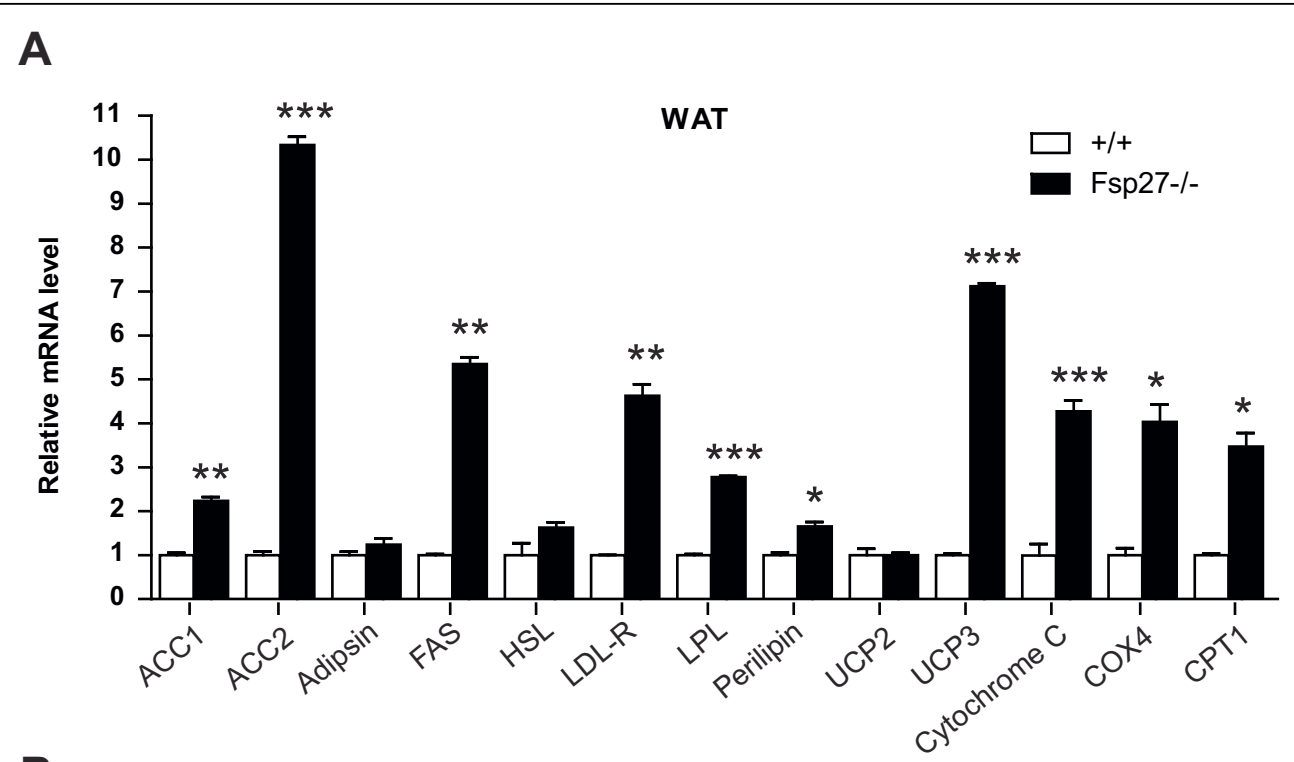

B

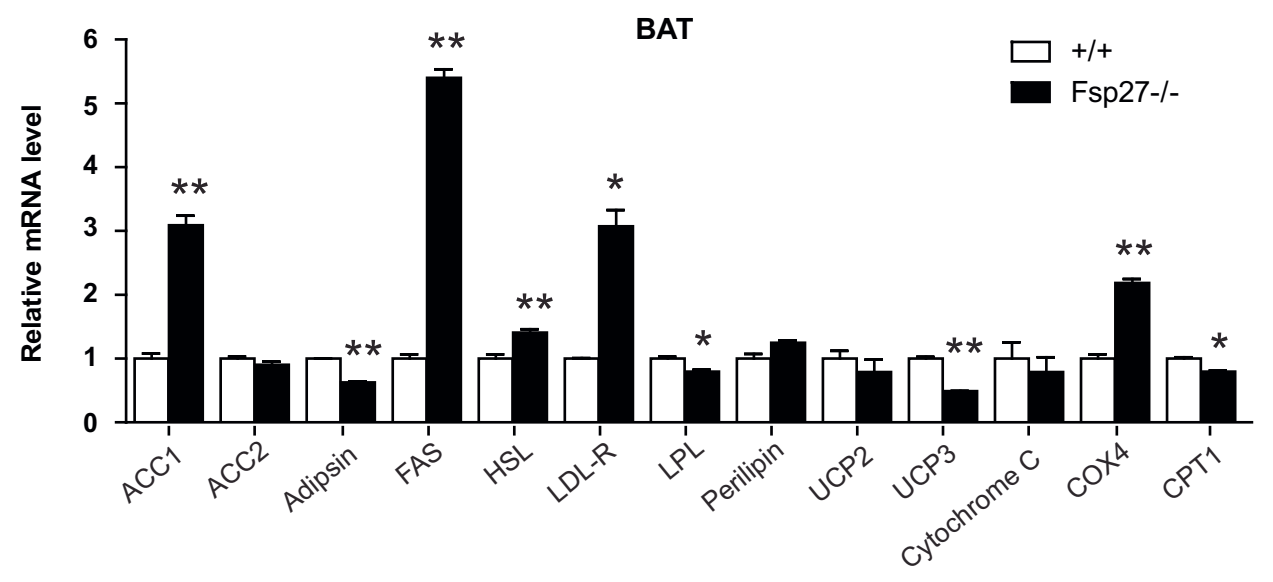

C

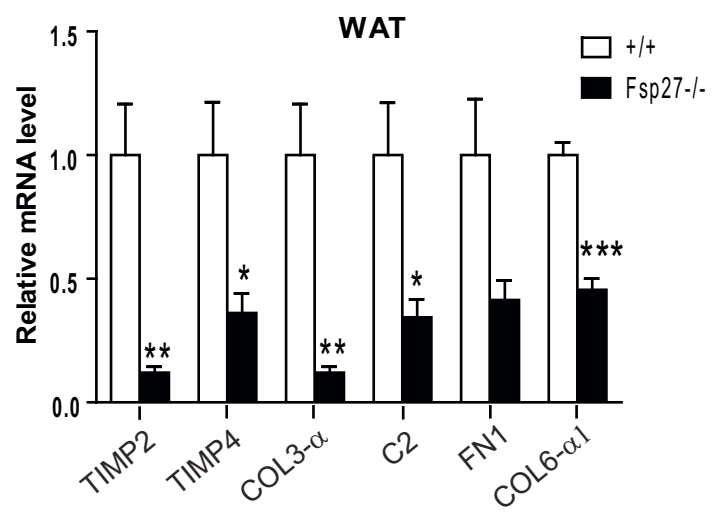

D

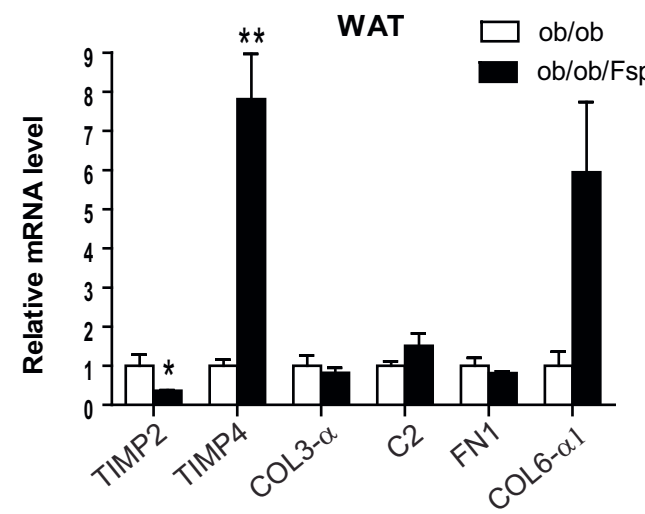

Figure 4 Altered gene expressions in various metabolic pathways in the WAT of FSP27-deficient. (A \& B) Relative mRNA levels of genes in various metabolic pathways in the WAT $(\mathbf{A})$ and BAT (B) of wild-type $(+/+)$ and FSP27-deficient $\left(F S P 27^{\prime}\right)$ mice. (C \& D) Relative mRNA levels of genes in the classic complement and extracellular matrix remodeling pathways in the WAT of wild-type (+/+) and FSP27-null (FSP2 ${ }^{\prime}{ }^{-}$) mice (C) and of leptin-deficient $(o b / o b)$ and leptin/FSP27 double-deficient (ob/ob/FSP27 ${ }^{\prime-}$ ) mice (D). The bars represent the mean \pm S.E.M. ${ }^{* * * P}<0.001$, ${ }^{* *} P<0.01$ and ${ }^{*} P<0.05$. 


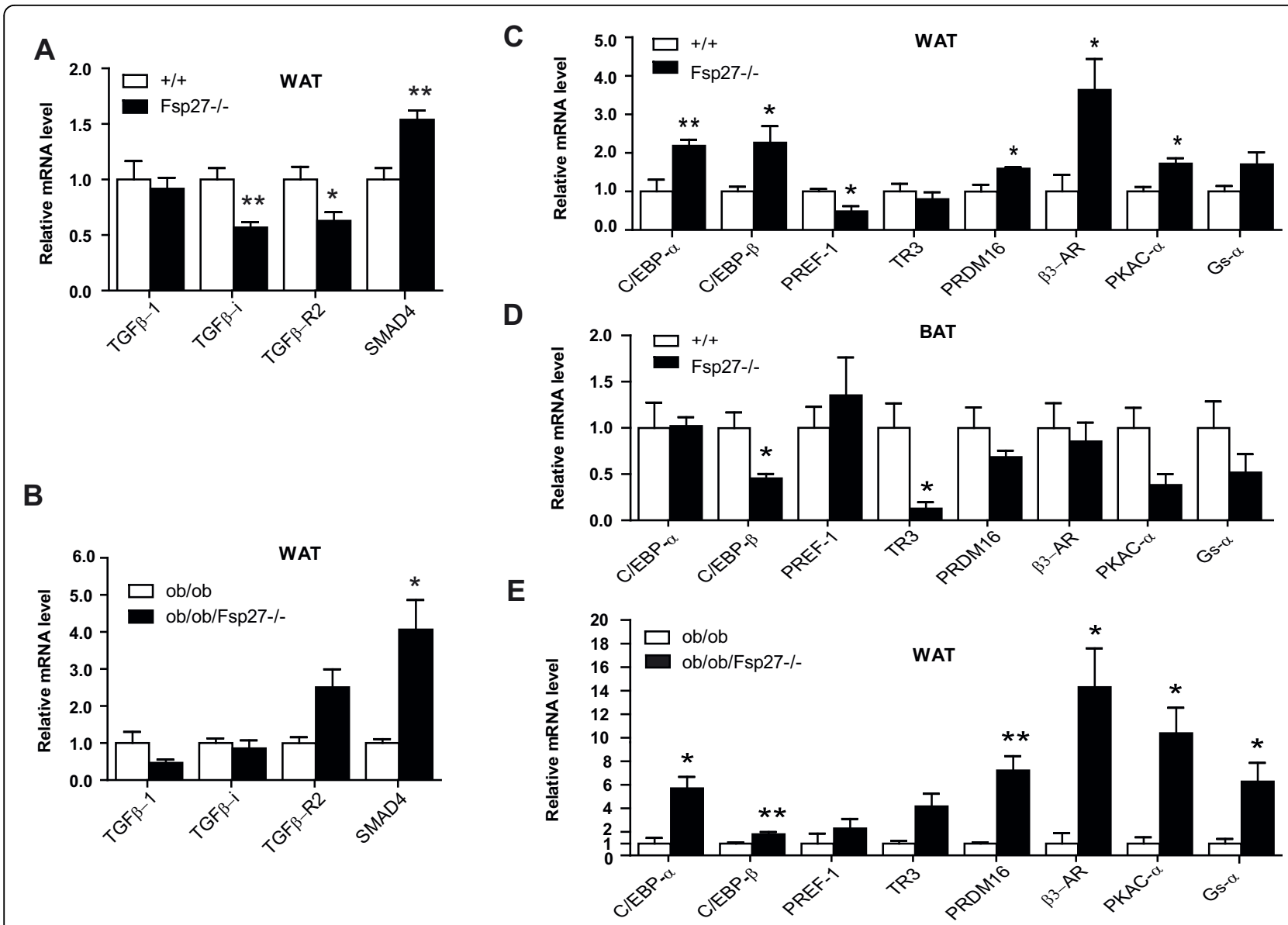

Figure 5 Expression levels of regulatory genes in the WAT of FSP27-deficient mice. (A \& B) Relative mRNA levels of genes in the TGF- $\beta$ pathway in the WAT of wild-type (+/+) and FSP27-null (FSP2 / $)$ mice $(\mathbf{A})$ and leptin-deficient (ob/ob) and leptin/FSP27 double-deficient (ob/ob/ FSP27 ${ }^{\prime}$ ) mice (B). (C \& D \& E) Relative mRNA levels of regulatory factors in the WAT $(\mathbf{C})$ and the BAT (D) of wild-type $(+/+)$ and FSP27-null $\left(F S P 27^{\prime}\right)$ mice and in the WAT of leptin-deficient (ob/ob) and leptin/FSP27 double-deficient (ob/ob/FSP27 ${ }^{\prime}$ ) mice (E). The bars represent the mean \pm S.E.M. ${ }^{* * P}<0.01$ and ${ }^{*} P<0.05$

were also up-regulated in the WAT of $o b / o b / F S P 27^{/-}$ mice (Figure 5E), which is consistent with the increased expression of BAT-selective genes in these mice. Furthermore, western blot analysis indicated that the protein levels of CEBP $\beta$ and $\beta 3$-AR were significantly increased (1.5- and 4-fold increases for CEBP $\beta$ and $\beta 3$ AR, respectively; Figure 6), which is consistent with their increased mRNA levels. The increased expression of BAT-selective genes (CIDEA and COX8b), CEBP $\beta$ and $\beta 3$-AR was also observed in the WAT of young female and old male FSP27-deficient mice (Additional file 4), suggesting that the acquisition of BAT-like properties in the WAT of FSP27-deficient mice occurs regardless of sex or age. Interestingly, the increased expression of PRDM16 was observed only in the WAT of young male and female $F S P 27^{1-}$ mice but not in the WAT of old mice, suggesting that the regulation of PRDM16 expression is age-dependent.

\section{Discussion}

Using microarray and qPCR analyses, we demonstrated that FSP27 plays an important role in regulating mitochondrial oxidative phosphorylation, adipocyte differentiation, lipolysis, fatty acid oxidation, the inflammatory response and the extracellular matrix structure by controlling extensive gene expression programs in both WAT and BAT. Semi-quantitative real-time PCR analyses validated the reliability of the microarray data (Additional file 5). Importantly, genes that are highly enriched in BAT (e.g., COX8b, ELOVL3 and LSDP5) were drastically up-regulated in the WAT of FSP27-deficient mice. In contrast, WAT-enriched genes (e.g., MEST and RETNL $\alpha$ ) were significantly down-regulated. The expression levels of the set of WAT-selective genes that were defined by Kajimura et al [30] were specifically examined in our microarray analyses (Additional file 6). A subset of these genes is down-regulated but others 


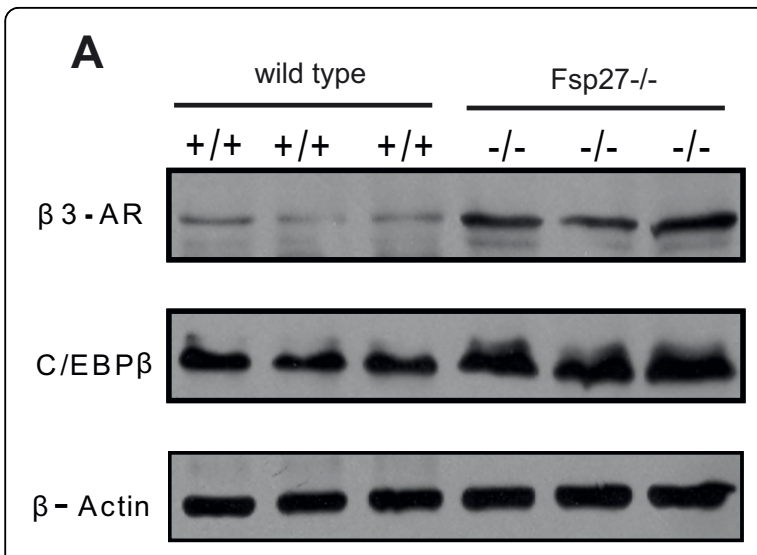

B

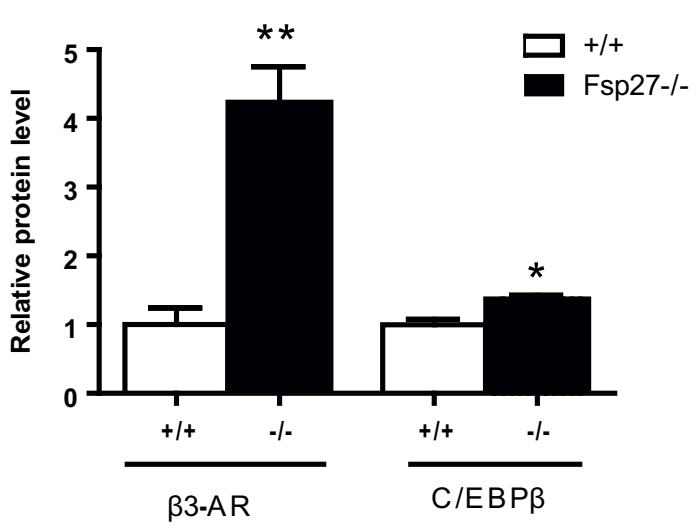

Figure 6 Increased $C / E B P \beta$ and $\mu 3-A R$ protein levels in the WAT of FSP27-null mice. (A) Western blot showing the increased protein levels of C/EBP $\beta$ and $\beta 3$-AR in the WAT of FSP27-deficient mice (-/-) compared with those of wild type mice $(+/+)$. $\beta$-actin was used as a loading control. (B) The intensity of the indicated protein bands in (A) was quantified using Quantity One software (BioRad, USA) and used for statistical analyses. The western blot analyses were performed in triplicate. The relative protein levels in the wild type mice were designated as 1.0. ${ }^{*} P<0.01$ and ${ }^{*} P<0.05$.

are up-regulated, suggesting that these genes are controlled by different mechanisms. The BAT-like phenotype of FSP27-deficient WAT was further supported by its significantly elevated expression of many genes involved in the regulation of the TCA cycle, the electron transport chain, uncoupling activity and the fatty acid oxidation pathway, resulting in its conversion from an energy storage organ to an energy consumption organ. The increased expression of BAT-selective genes and enhanced expression of genes involved in various metabolic pathways in the WAT of FSP27/- mice are likely due to the up-regulation of several regulatory factors: 1 ) CEBP $\alpha$ and CEBP $\beta$, which activate PPAR $\gamma$ expression and promote adipogenesis; 2) PRDM16, which promotes the differentiation of preadipocytes and myoblasts into brown adipocytes; 3) PPAR $\alpha / \gamma$ and PGC1 and their downstream target genes [42]; and 4) several genes in the cAMP signaling pathway (e.g., $\beta 3$-AR, PKAC- $\alpha$ and Gs- $\alpha$ ), which promote the conversion of white to brown adipocytes by inducing UCP1 expression and mitochondrial activity in white adipose depots. Therefore, the upregulation of CEBP $\alpha / \beta$ and PRDM16 may act as an initial step to increase the expression of PPAR $\alpha / \gamma$ and PGC1 and promote adipocyte differentiation. The increased expression of PPAR $\alpha / \gamma, \mathrm{PGC} 1$ and the proteins involved in CAMP signaling in conjunction with the reduced expression of $\mathrm{Rb}, \mathrm{P} 107$ and RIP140 [42] may act in concert to up-regulate genes specifically expressed in BAT and genes involved in energy metabolism, which in turn would promote the conversion of WAT to a BAT-like tissue in FSP27-deficient mice.

The underlying mechanism responsible for the increased expression of CEBP $\beta$ and PRDM16 in the WAT of FSP27-deficient mice is not understood. PREF1 , which inhibits adipocyte differentiation via the upregulation of SOX9, was down-regulated, likely resulting in a reduction in the expression levels of SOX9 [52,53]. SOX9 can bind to the promoters for CEBP $\beta$ and CEBP $\delta$, which would consequently suppress the activity of those promoters resulting in the reduced expression of PREF-1 and possibly SOX9 in the WAT of FSP27deficient mice. This cascade of events could, therefore, lead to the up-regulation of $C E B P \beta / \delta$. In addition, adiponectin was up-regulated in the WAT of FSP27-deficient mice (Fig. 3D). Adiponectin and its receptors have been reported to induce extracellular $\mathrm{Ca}^{2+}$ influx and activate $\mathrm{Ca}^{2+}$ /calmodulin-dependent protein kinase kinase beta (CaMKK $\beta)$, AMPK and SIRT1, resulting in an increase in the expression of PGC-1 $\alpha$ [54]. Therefore, the up-regulation of adiponectin may contribute to the increased levels of BAT-specific genes. In addition, CEBP $\beta$ has been shown to be phosphorylated and activated in response to an increase in the intracellular calcium concentration, which was caused by the activation of CaMKK $\beta$ [55]. The mechanism responsible for the transcriptional regulation of CEBP $\beta$ and PRDM16 in the WAT of FSP27 deficient mice remains to be clarified.

Our previous study indicated that the conversion of WAT to a BAT-like tissue in FSP27-deficient mice could be partially recapitulated in differentiated mouse embryonic fibroblasts (MEFs) isolated from FSP27-deficient mice. The differentiated FSP27-deficient MEFs showed characteristics such as increased lipolysis, smaller but multiple lipid droplets and reduced TAG storage. More importantly, the FSP27-deficient MEFs had an increased rate of fatty acid oxidation and higher expression levels of PGC1 $\alpha$, CIDEA, UCP1 and COX4 in the 
presence of T3 [42]. The relative expression levels of these BAT-selective genes in differentiated FSP27-deficient MEFs, however, were not as high as those seen in the WAT of FSP27-deficient mice [42]. For example, the mRNA levels of CIDEA and UCP1 are similar between wild-type and FSP27 $7^{-1-}$ MEFs, and the level of COX4 was 1.5-fold higher in FSP27 $7^{-1-}$ MEFs compared with that of wild-type cells. In the FSP27-deficient WAT, in contrast, mRNA levels of these three genes were 2.6-, 16.8- and 2.3-fold increased, respectively [42]. In addition, there was no difference in the expression of BATselective genes and mitochondrial activity between differentiated wild-type and FSP27 knock-down 3T3-L1 cells (data not shown). In differentiated FSP27 knockdown 3T3-L1 cells, Keller et al. also observed no difference in the expression of BAT-selective genes [56]. The discrepancy between the WAT of FSP27-deficient mice and in vitro cultured FSP27 deficient adipocytes may be due to the lack of crucial extracellular factors that cooperate with FSP27 to determine the BAT identity in cultured adipocytes. Alternatively, the commitment to the transition of WAT into BAT-like tissue in $F S P 27^{/-}$mice may occur before differentiation at the precursor stage. Further experiments will be needed to distinguish these possibilities.

Interestingly, there was a significantly reduced expression of genes involved in TGF- $\beta$ signaling in the WAT of FSP2 $7^{1-}$ mice. Because activation of the TGF- $\beta$ signaling pathway was shown to inhibit adipocyte differentiation [57], reduced TGF- $\beta$ signaling may further enhance white adipocyte differentiation in FSP27-deficient mice. The classic complement pathway, which plays a key role in the initiation of the inflammatory response in adipose tissue under obese and insulin-resistant conditions [58], was significantly down-regulated in the WAT of FSP27-deficient mice, implicating a reduced inflammatory response in the WAT. These data were also consistent with our previous observation that FSP27-deficient mice had improved insulin sensitivity and a lean phenotype $[42,46]$. Finally, a significantly reduced expression of collagen family proteins, MMPs and TIMPs, which all play key roles in determining the three-dimensional (3-D) structure of the WAT and in controlling extracellular matrix (ECM) remodeling [59-62], was observed in the WAT of FSP27-deficient mice. These data suggest that the 3-D structure and, in particular, the ECM structure of FSP27-deficient WAT is different from that of wild-type mice, which may be reflected in its reduced adipocyte size and reduced inflammatory response. As main components of extracellular matrix, the levels of collagen family proteins are generally up-regulated in the adipose tissue of diabetic mice [60]. In addition, animals with a disruption of collagen VI, a predominant collagen in adipose tissue, have larger adipocytes but improved insulin sensitivity [62]. The decreased ECM pathway may contribute to the reduced lipid storage in white adipocytes and the improved insulin sensitivity in FSP27-deficient mice.

Using leptin/FSP27 double deficient mice as a model system, the expression of BAT-selective genes and regulatory factors was analyzed under the conditions of FSP27 deficiency and obesity. BAT-selective genes and key metabolic regulators (e.g., CEBP $\alpha / \beta$ and PRDM16) and members of the cAMP signaling pathway (e.g., $\beta 3$ AR, PKAC- $\alpha$ and Gs- $\alpha$ ) were all up-regulated in the FSP27/leptin double deficient mice, which is consistent with that seen under the condition of FSP27 deficiency alone. Thus, white adipocytes in FSP27 and leptin double deficient mice also acquire BAT-like properties and become an energy consuming organ. The expression profile of the genes involved in TGF- $\beta$ signaling, extracellular matrix remodeling and the classic complement pathway in the WAT of $o b / o b / F S P 27^{1-}$ mice, however, was different from that of FSP27 deficient mice. This observation indicated that gene expression in these pathways in obese animals requires the cooperative action of FSP27 and other extrinsic factors.

Paradoxically, the gene expression profile in the BAT of FSP27-deficient mice was dramatically different from that of the FSP27-deficient WAT based on the following observations: 1) in the BAT of FSP27-deficient mice, there was a significantly increased expression of WATselective markers (MEST and RETNL $\alpha$ ) that are normally suppressed by the expression of PRDM16; 2) the expression of several mitochondrial genes (UCP3 and CPT1) was down-regulated; and 3) the expression levels of regulatory factors including CEBP $\beta$ and TR3 were reduced in the BAT of FSP27-deficient mice, whereas the expression of components in the cAMP pathway was similar to that of wild-type mice. The mechanism by which the expression profile of BAT of FSP27-deficient mice differs from that of WAT remains unclear. Given that CIDEA is expressed at a high level in BAT, it may replace FSP27 and perform some of the functions of FSP27. Further analysis using CIDEA/FSP27 double knock-out mice will be needed to address the role of these individual genes in BAT.

\section{Conclusions}

Overall, our data suggest that FSP27 acts as a crucial factor that controls the expression of genes involved in various regulatory and metabolic pathways in WAT and BAT. FSP27 deficiency results in the up-regulation of regulatory factors that promote the activation of BATselective genes and genes involved in energy expenditure processes such as mitochondrial activity. The coordinated regulation of such profound transcriptional networks that affect multiple metabolic and signaling 
pathways is an interesting property of FSP27-deficient mice. Although the precise mechanism by which FSP27 regulates these gene expression programs is not clear, our study strongly suggests that FSP27 is an important molecular determinant in controlling gene expression networks and in maintaining white adipocyte identity.

\section{Methods}

\section{Animal breeding and maintenance}

FSP27-deficient (FSP27 $7^{/-}$) mouse breeding and maintenance were essentially performed as described previously [42]. The Leptin/FSP27 double deficiency (ob/ob/ FSP2 $7^{1-}$ ) mice were generated by crossing $F S P 27^{1-}$ mice with heterozygous $o b /+$ mice (B6.V-Lepob/J) in a C57BL/6 background that were obtained from The Jackson Laboratories (Bar Harbor, ME). Genotyping for FSP27 and leptin deficiency in the offspring was performed as described previously [42,63]. The ob/ob/ $F S P 27^{-1-}$ littermates were compared with their leptin deficient $(o b / o b)$ littermates. The FSP27 $7^{-/}$and $o b / o b /$ FSP27 $7^{1-}$ mice were fed a normal chow diet (5053, PicoLab Rodent Diet 20). Mouse experiments were carried out in the animal facility in the School of Life Sciences, Tsinghua University. Mouse handling procedures were in accordance with the Responsible Care and Use of Laboratory Animals (RCULA) guidelines set by Tsinghua University. All research and experimental protocols involving mice were reviewed and approved by the animal research committee of Tsinghua University.

\section{RNA extraction, RT-PCR, semi-quantitative real-time RT-PCR and microarray analyses}

Gonadal WAT or interscapular BAT from 3- or 9month-old mice were dissected and quickly frozen in liquid nitrogen upon sacrifice and then stored at $-80^{\circ} \mathrm{C}$ for subsequent total RNA extraction. Total RNA from gonadal WAT or interscapular BAT was isolated individually using the TRIzol reagent (Invitrogen, USA) and quantified spectrophotometrically at 260/280 nm. The integrity of all RNA samples was evaluated on a $1 \%$ agarose gel, and all RNA samples were found to be pure with no degradation caused by the isolation procedure. For semi-quantitative real-time RT-PCR (qPCR) analysis, RNA isolated from four individual animals for each genotype was used for independent qPCR analysis. The first-strand cDNAs were synthesized from $2 \mu \mathrm{g}$ of total RNA in a total volume of $20 \mu \mathrm{l}$ using oligo- $(\mathrm{dT})_{20}$ primers and the Superscript III RT kit at $50^{\circ} \mathrm{C}$ for 60 mins according to the manufacturer's protocol (Invitrogen, USA). The reaction was inactivated by incubating the reaction mixture at $70^{\circ} \mathrm{C}$ for 15 minutes, followed by the removal of RNA complementary to the cDNA with $1 \mu \mathrm{l}$ (2 units) of E. coli RNase $\mathrm{H}$ (Invitrogen, USA) at $37^{\circ} \mathrm{C}$ for 20 minutes. The cDNA samples were then diluted with sterile deionized water to a total volume of $200 \mu \mathrm{l}$, and $2 \mu \mathrm{l}$ was used for each qPCR reaction.

qPCR analysis was performed using the ABI SYBR Green PCR Master Mix in the MX3000P real-time PCR system (Stratagene, USA) according to the manufacturer's protocol. Primer sequences, annealing temperatures and the size of each amplified PCR product are given in Additional file 7. A BLAST search against the mouse genome using the electronic PCR program from the NCBI Genome Database of the primer pairs confirmed that no genomic or pseudogene PCR products would be amplified. $\beta$-actin was used as an internal control for the qPCR analyses. To validate its reliability during the analyses, another common internal control, cyclophilin (an ER specific protein), was used to evaluate the expression levels of $\beta$-actin. Its expression was similar between wild-type and FSP27deficient mice. In addition, the expression levels of representative genes (leptin and Collagen-6 $\alpha 1$ ) using cyclophilin as the internal control were similar to those using $\beta$ actin as the internal control, indicating that $\beta$-actin was a reliable internal control for the normalization of our qPCR results (Additional file 8 ).

For microarray analyses, equal amounts of total RNA from five pairs of three-month-old male FSP27-deficient mice were combined to form RNA pools (total amount of $45 \mu \mathrm{g}$ ). Affymetrix gene chips (Mouse Genome 430 2.0A arrays, Affymetrix, USA) were used for hybridization and data collection. The protocol was performed by the Microarray Facility at the Institute of Molecular and Cell Biology in Singapore. The microarray data were processed with the Affymetrix GeneChip Operating Software (GCOS) and submitted to the GEO repository for the Series record (GSE22693). The gene set enrichment analysis (GSEA) was performed as previously described [64]. The microarray data from PPAR $\alpha$-deficient WAT, PGC1 $\alpha / P G C 1 \beta$ double-deficient brown fat cells and PPAR 2 over-expressing NIH3T3 cells were extracted from the Gene Expression Omnibus with the accession numbers GSE2131[65], GSE5042 [50] and GSE2192 [66], respectively.

\section{Western blot analysis}

Cell lysates from the WAT of wild type and $F S P 27^{-1-}$ 3-month-old male mice were obtained by homogenizing the tissues in RIPA buffer (20 mM HEPES-KOH pH 7.5, $150 \mathrm{mM} \mathrm{NaCl}, 1 \mathrm{mM}$ EDTA, 10\% Glycerol, 0.5\% sodium deoxycholate, $1 \%$ NP40, 0.1\% SDS and protease inhibitor) and subsequently used for western blot analysis as previously described [36]. Antibodies against $\beta$-actin (Sigma, USA) as well as $\beta 3$-AR and CEBP $\beta$ (Santa Cruz, USA) were used for the western blot analyses. Protein bands were visualized by an Enhanced Chemiluminescence detection system and quantified by densitometry analysis using Quantity One (Bio-Rad, USA). The experiments were performed in triplicate. 


\section{Statistical analysis}

All data were presented as means \pm S.E.M. Differences between groups were assessed by a two-tailed, nonpaired or paired Student's t-test using the Graph Pad Prism statistics software (GraphPad Software Inc.)

\section{Additional material}

Additional file 1: Significantly upregulated pathways in Fsp27deficient WAT. Genes are grouped according to their function and listed in the alphabetical order under each heading. The last number represents the total genes in one gene set. The middle is the changed (criteria is designated as fold change between wildtype and Fsp27 -/mice is more than \pm 1.41 ) gene number,

Additional file 2: Factors that inhibit BAT differentiation were down-regulated in the WAT of FSP27-/- mice.

Additional file 3: Significantly down-regulated pathways in the WAT of Fsp27-null mice. Genes are grouped according to their function and listed in alphabetical order under each heading. The last number represents the total number of genes in one gene set. The middle number represents the number of genes with an altered expression pattern (criteria designated as a fold-change between wildtype and Fsp27 -/- mice of more than \pm 1.41 ). The first number represents the number of upregulated or downregulated genes in that gene set.

Additional file 4: Expression of BAT-selective genes and the major regulators in the WAT of young female or old male FSP27 deficient mice. (A \& B) Relative mRNA levels of BAT-specific genes and the main regulatory factors in the WAT of three-month-old female $(\mathbf{A})$ or ninemonth-old male (B) wild type $(+/+)$ and FSP27 null $\left(F S P 27^{-/}\right)$mice.

Additional file 5: Comparison of microarray and $\mathrm{QPCR}$ analyses. $\mathrm{A}$ total of 52 genes were analyzed by qPCR in the current study and a previous report [Ref [42]]. Among these 52 validated genes, 34 were determined to be up- or down-regulated by microarray analysis, and 30 of those 34 genes (88\%) were consistently validated by qPCR. The increased sensitivity of qPCR allowed the detection of alterations in the expression levels of low abundant gene such as PREF-1. Only Smad4 expression showed opposite results in the two analyses. N/A: not available; NC: no change according to the given criteria; + : increase; $-:$ decrease.

Additional file 6: Altered profiles of WAT-selective genes in FSP27deficient WAT. The list of WAT-selective genes is taken from Reference 30. These genes were determined to be differentially expressed in FSP27deficient WAT by microarray analysis

Additional file 7: Primer sequences for the genes involved in the qPCR analysis.

Additional file 8: Validation of $\beta$-actin as a reliable internal control for the qPCR data analyses. (A) Relative mRNA levels of leptin,

Collagen 6 alpha1 (COL6- $\alpha 1$ ) and cyclophilin using $\beta$-actin as an internal control for the normalization of aPCR results. Reduced levels of leptin and COL6- $\alpha 1$ expression but a similar level of cyclophilin expression were observed in the WAT of FSP27 null mice (FSP27'-) compared with those of wild type mice $(+/+)$. (B) Relative mRNA levels of leptin, COL6$\alpha 1$ and $\beta$-actin using cyclophilin as an internal control for the normalization of qPCR results. Reduced levels of leptin and COL6- $\alpha 1$ expression but a similar level of $\beta$-actin expression in the WAT of FSP27 null mice $\left(F S P 2 T^{\prime}\right)$ compared with those of wild type mice $(+/+)$. Both data sets are consistent and validate the use of $\beta$-actin as a reliable internal control for $\mathrm{QPCR}$ analysis.

\section{Abbreviations}

ACC1/2: acetyl-CoA carboxylase 1/2; BAT: brown adipose tissue; $\beta 3$-AR: beta3 adrenergic receptor; $C 2$ : complement factor 2; CEBP $\alpha / \beta$ : CCAAT/enhancer binding protein alpha/beta; COL3- $\alpha$ : collagen type 3-alpha; COL6- $\alpha$ 1: collagen type 6-alpha1; COX 4: cytochrome oxidase 4; COX 8b: cytochrome C oxidase subunit 8b; CPT1: carnitine palmitoyltransferase l; DIO2: type 2 iodothyronine deiondinase; ECM: extracellular matrix; ELOVL3: elongation of very long chain fatty acid-3; FAS: fatty acid synthase; Fn1: fibronectin 1; FSP27: fat specific protein 27; G $\alpha$-s: Gs alpha subunit; HSL: hormone sensitive lipase; LDLR: low density lipoprotein receptor; LPL: lipoprotein lipase; LSDP5: lipid storage droplet protein 5; MEST: mesoderm specific transcript; PGC1 $\alpha$ : peroxisome proliferator-activated receptor gamma coactivator 1 alpha; PKAC $\alpha$ : protein kinase A catalytic subunit alpha; PPAR: peroxisome proliferator-activated receptor; PRDM16: PR domain containing 16; PREF-1: preadipocyte factor 1; RETNLo: resistin related protein alpha; SMAD4: SMAD family member 4; TAG: triacylglycerol; TCA: tricarboxylic acid cycle; TGF- $\beta$ : transforming growth factor beta; TGF $\beta$-I: Transforming growth factor beta inducible protein; TGF $\beta$-R2: TGF beta receptor 2; TIMP2/4: tissue inhibitor of metalloprotease 2 and 4; TR3: thyroid hormone receptor; UCP1/2/3: uncoupling protein 1,2 and 3; WAT: white adipose tissue.

\section{Acknowledgements}

We thank members of Peng Li's laboratory at Tsinghua University for their technical assistance and helpful discussions. This work was supported by grants from the National Basic Research Program of China (2007CB914404 to $\mathrm{PL}$ ), the Ministry of Science and Technology of China and the National Nature Science Foundation of China (30800555 to LX, 30925017 to PL). This work was also supported by the Program for Changjiang Scholars and the Innovative Research Team at the University of the Ministry of Education in China (to PL), the China Postdoctoral Science Foundation (20080430414 to $L X)$ and the Scientific Research Foundation for the Returned Overseas Chinese Scholars from the Ministry of Education of China (to LX).

\section{Author details}

${ }^{1}$ College of Life Sciences, Beijing Normal University Xinjiekouwai Street 19, Xichen District Beijing 100875, China. ${ }^{2}$ Protein Science Laboratory of the Ministry of Education, School of Life Sciences, Tsinghua University, Qinghuayuan, Haidian District, Beijing 100084, China. ${ }^{3}$ College of Life Science and Bioengineering, Beijing Jiaotong University, Shangyuancun 3, Haidian District, Beijing 100044, China. ${ }^{4}$ Department of Biology, Hong Kong University of Science and Technology, Clearwater Bay, Kowloon, Hong Kong. ${ }^{5}$ Department of Biochemistry, Hong Kong University of Science and Technology, Clearwater Bay, Kowloon, Hong Kong.

\section{Authors' contributions}

DL maintained the animals, performed mouse genotyping, isolated the mouse tissues, generated the RNA from these tissues and performed the majority of the GPCR experiments. DL was also responsible for the organization of the final manuscript figures. $Y Z$ performed the bioinformatic analyses of the microarray data. LX helped maintain the animals, performed western blot analyses, performed data analyses and helped revise the manuscript. YW helped with the GPCR analyses. BX performed some of the qPCR experiments. LZ and LX maintained the ob/ob/FSP27 double knock-out mice and provided tissues for the GPCR analyses. ZW helped with the microarray analyses. PL and JS were responsible for the experimental design as well as the data coordination, analysis and interpretation. PL and JS were responsible for the writing, revision and finalization of the manuscript as well as for the decision to submit the manuscript for publication. All authors read and approved the final manuscript.

Received: 5 January 2010 Accepted: 22 July 2010

Published: 22 July 2010

\section{References}

1. Gesta S, Tseng YH, Kahn CR: Developmental origin of fat: tracking obesity to its source. Cell 2007, 131:242-256.

2. Merklin RJ: Growth and distribution of human fetal brown fat. Anat Rec $1974,178: 637-646$

3. Lean MEJ: Brown adipose tissue in humans. Proc Nutr Soc 1989, 48:243-256.

4. Virtanen KA, Lidell ME, Orava J, Heglind M, Westergren R, Niemi T, Taittonen M, Laine J, Savisto NJ, Enerbäck S, Nuutila P: Functional brown adipose tissue in healthy adults. N Engl J Med 2009, 360:1518-1525.

5. Cypess AM, Lehman S, Williams G, Tal I, Rodman D, Goldfine AB, Kuo FC, Palmer EL, Tseng YH, Doria A, Kolodny GM, Kahn CR: Identification and importance of brown adipose tissue in adult humans. N Engl J Med 2009, 360:1509-1517. 
6. van Marken Lichtenbelt WD, Vanhommerig JW, Smulders NM, Drossaerts JM, Kemerink GJ, Bouvy ND, Schrauwen P, Teule GJ: Coldactivated brown adipose tissue in healthy men. N Engl J Med 2009, 360:1500-1508.

7. Carmen GY, Víctor SM: Signalling mechanisms regulating lipolysis. Cell Signal 2006, 18:401-408.

8. Smith SA: Central role of the adipocyte in the insulin-sensitising and cardiovascular risk modifying actions of the thiazolidinediones. Biochimie 2003, 85:1219-1230.

9. Golozoubova V, Hohtola E, Matthias A, Jacobsson A, Cannon B, Nedergaard J: Only UCP1 can mediate adaptive nonshivering thermogenesis in the cold. FASEB J 2001, 15:2048-2050.

10. Silva JE, Larsen PR: Adrenergic activation of triiodothyronine production in brown adipose tissue. Nature 1983, 305:712-713.

11. Jakobsson A, Westerberg R, Jacobsson A: Fatty acid elongases in mammals: their regulation and roles in metabolism. Prog Lipid Res 2006, 45:237-249.

12. Jakobsson A, Jörgensen JA, Jacobsson A: Differential regulation of fatty acid elongation enzymes in brown adipocytes implies a unique role for Elovl3 during increased fatty acid oxidation. Am J Physiol Endocrinol Metab 2005, 289:E517-526.

13. Westerberg R, Månsson JE, Golozoubova V, Shabalina IG, Backlund EC, Tvrdik P, Retterstøl K, Capecchi MR, Jacobsson A: ELOVL3 is an important component for early onset of lipid recruitment in brown adipose tissue. J Biol Chem 2006, 281:4958-4968.

14. Unami A, Shinohara Y, Kajimoto K, Baba Y: Comparison of gene expression profiles between white and brown adipose tissues of rat by microarray analysis. Biochem Pharmacol 2004, 67:555-564.

15. Seale P, Kajimura S, Yang W, Chin S, Rohas LM, Uldry M, Tavernier G, Langin D, Spiegelman BM: Transcriptional control of brown fat determination by PRDM16. Cell Metab 2007, 6:38-54

16. Yamaguchi T, Matsushita S, Motojima K, Hirose F, Osumi T: MLDP, a novel PAT family protein localized to lipid droplets and enriched in the heart, is regulated by peroxisome proliferator-activated receptor alpha. J Biol Chem 2006, 281:14232-14240.

17. Wolins NE, Quaynor BK, Skinner JR, Tzekov A, Croce MA, Gropler MC, Varma V, Yao-Borengasser A, Rasouli N, Kern PA, Finck BN, Bickel PE: OXPAT/PAT-1 is a PPAR-induced lipid droplet protein that promotes fatty acid utilization. Diabetes 2006, 55:3418-3428.

18. Dalen KT, Dahl T, Holter E, Arntsen B, Londos C, Sztalryd C, Nebb HI: LSDP5 is a PAT protein specifically expressed in fatty acid oxidizing tissues. Biochim Biophys Acta 2007, 1771:210-227.

19. Puigserver $P$, Wu Z, Park CW, Graves $R$, Wright $M$, Spiegelman BM: A coldinducible coactivator of nuclear receptors linked to adaptive thermogenesis. Cell 1998, 92:829-839.

20. Wu Z, Puigserver P, Andersson U, Zhang C, Adelmant G, Mootha V, Troy A, Cinti S, Lowell B, Scarpulla RC, Spiegelman BM: Mechanisms controlling mitochondrial biogenesis and respiration through the thermogenic coactivator PGC-1. Cell 1999, 98:115-124.

21. Lin J, Handschin C, Spiegelman BM: Metabolic control through the PGC-1 family of transcription coactivators. Cell Metab 2005, 1:361-370.

22. Chao LC, Bensinger SJ, Villanueva CJ, Wroblewski K, Tontonoz P: Inhibition of adipocyte differentiation by Nur77, Nurr1, and Nor1. Mol Endocrinol 2008, 22:2596-608.

23. Kanzleiter T, Schneider T, Walter I, Bolze F, Eickhorst C, Heldmaier G, Klaus S, Klingenspor M: Evidence for Nr4a1 as a cold-induced effector of brown fat thermogenesis. Physiol Genomics 2005, 24:37-44.

24. Takahashi $M$, Kamei $Y$, Ezaki O: Mest/Peg1 imprinted gene enlarges adipocytes and is a marker of adipocyte size. Am J Physiol Endocrinol Metab 2005, 288:E117-124.

25. Nikonova L, Koza RA, Mendoza T, Chao PM, Curley JP, Kozak LP: Mesoderm-specific transcript is associated with fat mass expansion in response to a positive energy balance. FASEB J 2008, 22:3925-3937.

26. Steppan CM, Bailey ST, Bhat S, Brown EJ, Banerjee RR, Wright CM, Patel HR, Ahima RS, Lazar MA: The hormone resistin links obesity to diabetes. Nature 2001, 409:307-312.

27. Steppan CM, Brown EJ, Wright CM, Bhat S, Banerjee RR, Dai CY, Enders GH, Silberg DG, Wen X, Wu GD, Lazar MA: A family of tissue-specific resistinlike molecules. Proc Natl Acad Sci USA 2001, 98:502-506.

28. Rajala MW, Lin Y, Ranalletta M, Yang XM, Qian H, Gingerich R, Barzilai N, Scherer PE: Cell type-specific expression and coregulation of murine resistin and resistin-like molecule-alpha in adipose tissue. Mol Endocrinol 2002, 16:1920-1930.

29. Ailhaud G, Grimaldi P, Negrel R: Cellular and molecular aspects of adipose tissue development. Annu Rev Nutr 1992, 12:207-233.

30. Kajimura S, Seale P, Tomaru T, Erdjument-Bromage $H$, Cooper MP, Ruas JL, Chin S, Tempst P, Lazar MA, Spiegelman BM: Regulation of the brown and white fat gene programs through a PRDM16/CtBP transcriptional complex. Genes Dev 2008, 22:1397-1409.

31. Seale $P$, Bjork $B$, Yang $W$, Kajimura $S$, Chin $S$, Kuang $S$, Scimè $A$, Devarakonda S, Conroe HM, Erdjument-Bromage H, Tempst P, Rudnicki MA, Beier DR, Spiegelman BM: PRDM16 controls a brown fat/skeletal muscle switch. Nature 2008, 454:961-967.

32. Kajimura S, Seale P, Kubota K, Lunsford E, Frangioni JV, Gygi SP, Spiegelman BM: Initiation of myoblast to brown fat switch by a PRDM16C/EBP-beta transcriptional complex. Nature 2009, 460:1154-1158.

33. Bouillaud F, Ricquier D, Mory G, Thibault J: Increased level of mRNA for the uncoupling protein in brown adipose tissue of rats during thermogenesis induced by cold exposure or norepinephrine infusion. J Biol Chem 1984, 259:11583-11586.

34. Yoshida T, Umekawa T: Beta 3 adrenergic receptor polymorphism and obesity. Nippon Rinsho 1998, 56:1871-1875.

35. Himms-Hagen J, Melnyk A, Zingaretti MC, Ceresi E, Barbatelli G, Cinti S: Multilocular fat cells in WAT of CL-316243-treated rats derive directly from white adipocytes. Am J Physiol Cell Physiol 2000, 279:C670-681.

36. Gray SL, Dalla Nora E, Backlund EC, Manieri M, Virtue S, Noland RC, O'Rahilly S, Cortright RN, Cinti S, Cannon B, Vidal-Puig A: Decreased brown adipocyte recruitment and thermogenic capacity in mice with impaired peroxisome proliferator-activated receptor (P465L PPARgamma) function. Endocrinology 2006, 147:5708-5714.

37. Chiu CH, Lin WD, Huang SY, Lee YH: Effect of a C/EBP gene replacement on mitochondrial biogenesis in fat cells. Genes Dev 2004, 18:1970-1975.

38. Cederberg A, Grønning LM, Ahrén B, Taskén K, Carlsson P, Enerbäck S: FOXC2 is a winged helix gene that counteracts obesity, hypertriglyceridemia, and diet-induced insulin resistance. Cell 2001, 106:563-573

39. Gong J, Sun Z, Li P: CIDE proteins and metabolic disorders. Curr Opin Lipidol 2009, 20:121-126.

40. Li JZ, Ye J, Xue B, Qi J, Zhang J, Zhou Z, Li Q, Wen Z, Li P: Cideb regulates diet-induced obesity, liver steatosis, and insulin sensitivity by controlling lipogenesis and fatty acid oxidation. Diabetes 2007, 56:2523-2532.

41. Zhou Z, Yon Toh S, Chen Z, Guo K, Ng CP, Ponniah S, Lin SC, Hong W, Li P. Cidea-deficient mice have lean phenotype and are resistant to obesity. Nat Genet 2003, 35:49-56.

42. Toh SY, Gong J, Du G, Li JZ, Yang S, Ye J, Yao H, Zhang Y, Xue B, Li Q, Yang $H$, Wen Z, Li P: Up-regulation of mitochondrial activity and acquirement of brown adipose tissue-like property in the white adipose tissue of Fsp27 deficient mice. PLoS One 2008, 3:e2890.

43. Puri V, Ranjit S, Konda S, Nicoloro SM, Straubhaar J, Chawla A, Chouinard M Lin C, Burkart A, Corvera S, Perugini RA, Czech MP: Cidea is associated with lipid droplets and insulin sensitivity in humans. Proc Natl Acad Sci USA 2008, 105:7833-7838.

44. Puri V, Konda S, Ranjit S, Aouadi M, Chawla A, Chouinard M, Chakladar A, Czech MP: Fat-specific protein 27, a novel lipid droplet protein that enhances triglyceride storage. J Biol Chem 2007, 282:34213-34218.

45. Ye J, Li JZ, Liu Y, Li X, Yang T, Ma X, Li Q, Yao Z, Li P: Cideb, an ER- and lipid droplet-associated protein, mediates VLDL lipidation and maturation by interacting with apolipoprotein B. Cell Metab 2009, 9:177-190.

46. Nishino N, Tamori Y, Tateya S, Kawaguchi T, Shibakusa T, Mizunoya W, Inoue K, Kitazawa R, Kitazawa S, Matsuki Y, Hiramatsu R, Masubuchi S, Omachi A, Kimura K, Saito M, Amo T, Ohta S, Yamaguchi T, Osumi T, Cheng J, Fujimoto T, Nakao H, Nakao K, Aiba A, Okamura H, Fushiki T, Kasuga M: FSP27 contributes to efficient energy storage in murine white adipocytes by promoting the formation of unilocular lipid droplets. $J$ Clin Invest 2008, 118:2808-2821.

47. Karpova T, Danchuk S, Kolobova E, Popov KM: Characterization of the isozymes of pyruvate dehydrogenase phosphatase: implications for the regulation of pyruvate dehydrogenase activity. Biochim Biophys Acta 2003, 1652:126-135.

48. Sugawara S: Immune functions of proteinase 3. Crit Rev Immunol 2005, 25:343-360. 
49. Edwards SW, Tan CM, Limbird LE: Localization of G-protein-coupled receptors in health and disease. Trends Pharmacol Sci 2000, 21:304-308.

50. Uldry M, Yang W, St-Pierre J, Lin J, Seale P, Spiegelman BM: Complementary action of the PGC-1 coactivators in mitochondrial biogenesis and brown fat differentiation. Cell Metab 2006, 3:333-341.

51. Thapa N, Lee BH, Kim IS: TGFBIp/betaig-h3 protein: a versatile matrix molecule induced by TGF-beta. Int I Biochem Cell Biol 2007, 39:2183-2194

52. Smas CM, Sul HS: Pref-1, a protein containing EGF-like repeats, inhibits adipocyte differentiation. Cell 1993, 73:725-734.

53. Wang Y, Sul HS: Pref-1 regulates mesenchymal cell commitment and differentiation through Sox9. Cell Metab 2009, 9:287-302.

54. Iwabu M, Yamauchi T, Okada-Iwabu M, Sato K, Nakagawa T, Funata M, Yamaguchi M, Namiki S, Nakayama R, Tabata M, Ogata H, Kubota N, Takamoto I, Hayashi YK, Yamauchi N, Waki H, Fukayama M, Nishino I, Tokuyama K, Ueki K, Oike Y, Ishii S, Hirose K, Shimizu T, Touhara K, Kadowaki T: Adiponectin and AdipoR1 regulate PGC-1alpha and mitochondria by $\mathrm{Ca}(2+)$ and AMPK/SIRT1. Nature 2010, 464:1313-1319.

55. Wegner M, Cao Z, Rosenfeld MG: Calcium-regulated phosphorylation within the leucine zipper of C/EBP beta. Science 1992, 256:370-373.

56. Keller P, Petrie JT, De Rose P, Gerin I, Wright WS, Chiang SH, Nielsen AR, Fischer CP, Pedersen BK, MacDougald OA: Fat-specific protein 27 regulates storage of triacylglycerol. J Biol Chem 2008, 283:14355-14365.

57. Choy L, Skillington J, Derynck R: Roles of autocrine TGF-beta receptor and Smad signaling in adipocyte differentiation. J Cell Biol 2000, 149:667-682.

58. Zhang J, Wright W, Bernlohr DA, Cushman SW, Chen X: Alterations of the classic pathway of complement in adipose tissue of obesity and insulin resistance. Am J Physiol Endocrinol Metab 2007, 292:E1433-1440.

59. Baker AH, Edwards DR, Murphy G: Metalloproteinase inhibitors: biological actions and therapeutic opportunities. J Cell Sci 2002, 115:3719-3727.

60. Maquoi E, Munaut C, Colige A, Collen D, Lijnen HR: Modulation of adipose tissue expression of murine matrix metalloproteinases and their tissue inhibitors with obesity. Diabetes 2002, 51:1093-1101.

61. Chun TH, Hotary KB, Sabeh F, Saltiel AR, Allen ED, Weiss SJ: A pericellular collagenase directs the 3-dimensional development of white adipose tissue. Cell 2006, 125:577-591.

62. Khan T, Muise ES, lyengar P, Wang ZV, Chandalia M, Abate N, Zhang BB, Bonaldo P, Chua S, Scherer PE: Metabolic dysregulation and adipose tissue fibrosis: role of collagen VI. Mol Cell Biol 2009, 29:1575-1591.

63. Chehab FF, Lim ME, Lu R: Correction of the sterility defect in homozygous obese female mice by treatment with the human recombinant leptin. Nat Genet 1996, 12:318-320.

64. Subramanian A, Tamayo P, Mootha VK, Mukherjee S, Ebert BL, Gillette MA, Paulovich A, Pomeroy SL, Golub TR, Lander ES, Mesirov JP: Gene set enrichment analysis: a knowledge-based approach for interpreting genome-wide expression profiles. Proc Natl Acad Sci USA 2005, 102:15545-15550.

65. Li P, Zhu Z, Lu Y, Granneman JG: Metabolic and cellular plasticity in white adipose tissue II: role of peroxisome proliferator-activated receptoralpha. Am J Physiol Endocrinol Metab 2005, 289:E617-626.

66. Akerblad P, Månsson R, Lagergren A, Westerlund S, Basta B, Lind U, Thelin A, Gisler R, Liberg D, Nelander S, Bamberg K, Sigvardsson M: Gene expression analysis suggests that EBF-1 and PPARgamma2 induce adipogenesis of $\mathrm{NIH}-3 \mathrm{~T} 3$ cells with similar efficiency and kinetics. Physiol Genomics 2005, 23:206-216.

doi:10.1186/1471-2164-11-446

Cite this article as: Li et al:: Regulation of gene expression by FSP27 in white and brown adipose tissue. BMC Genomics 2010 11:446.

\section{Submit your next manuscript to BioMed Central and take full advantage of:}

- Convenient online submission

- Thorough peer review

- No space constraints or color figure charges

- Immediate publication on acceptance

- Inclusion in PubMed, CAS, Scopus and Google Scholar

- Research which is freely available for redistribution

Submit your manuscript at www.biomedcentral.com/submit
Biomed Central 